\title{
ERRATUM
}

V. A. Portyanko - G. Chen - H. W. Rines $\cdot$ R. L. Phillips

K. J. Leonard · G. E. Ochocki $\cdot$ D. D. Stuthman

\section{Quantitative trait loci for partial resistance to crown rust, Puccinia coronata, in cultivated oat, Avena sativa L.}

Published online: 5 November 2005

(C) Springer-Verlag 2005

\section{Theor Appl Genet (2005) 111:313-324}

Unfortunately, an incorrect version of Fig. 2 was published online and in print. The correct figure is given on the following two pages.

The online version of the original article can be found at http:// dx.doi.org/10.007/s00122-005-2024-6

\author{
V. A. Portyanko \\ Department of Plant Biology, University of Minnesota, \\ 250 BioSci Center, 1445 Gortner Avenue, St. Paul, \\ MN 55108, USA \\ G. Chen · D. D. Stuthman \\ Department of Agronomy and Plant Genetics, \\ University of Minnesota, 411 Borlaug Hall \\ 1991 Upper Buford Circle, St. Paul, MN 55108, USA
}

H. W. Rines $(\square)$

US Department of Agriculture, Agricultural Research Service,

Department of Agronomy and Plant Genetics,

University of Minnesota, 411 Borlaug Hall,

1991 Upper Buford Circle, St. Paul, MN 55108, USA

E-mail: rines001@umn.edu

Tel.: + 1-612-6255220

Fax: + 1-651-6495058

R. L. Phillips

Department of Agronomy and Plant Genetics,

Center for Microbial and Plant Genomics,

University of Minnesota, 411 Borlaug Hall,

1991 Upper Buford Circle, St. Paul, MN 55108, USA

K. J. Leonard · G. E. Ochocki

Cereal Disease Laboratory, US Department of Agriculture,

Agricultural Research Service, St. Paul, MN 55108, USA

Present address: G. Chen

Cereal Research Centre, Agriculture and Agri-Food Canada, 195 Dafoe Road, Winnipeg, MB R3T 2M9, Canada

Present address: K. J. Leonard

Department of Plant Pathology, University of Minnesota,

St. Paul, MN 55108, USA 


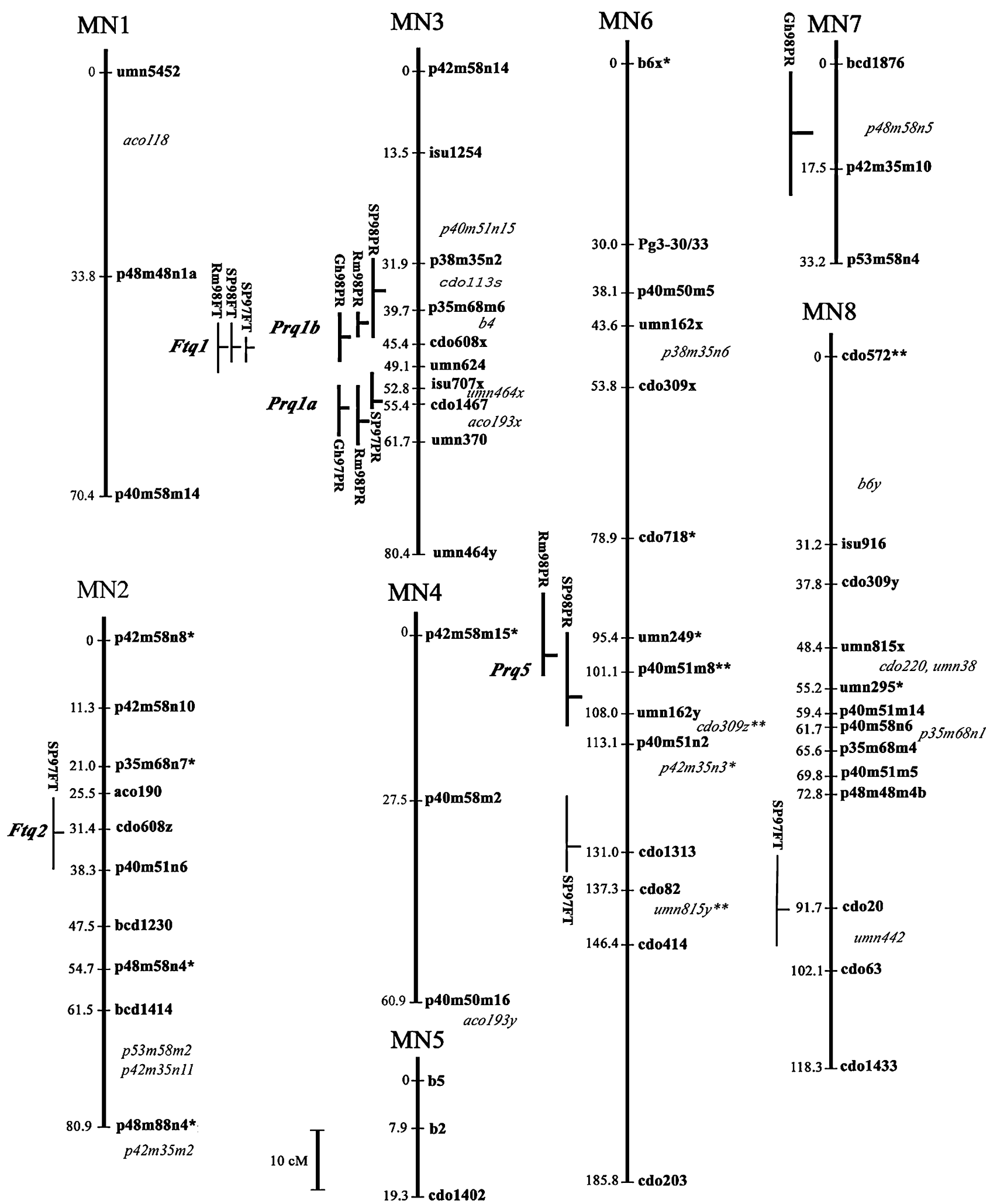

Fig. 2 A molecular linkage map of hexaploid oat based on $158 \mathrm{~F}_{6: 8}$ RILs from the cross MN841801-1×'Noble-2' with mapped quantitative trait loci (QTLs) for partial resistance to crown rust (Prq) and flowering time $(F t q)$. Numbers to the left of linkage groups are cumulative map distances in $\mathrm{cM}$ (Haldane). Marker loci shown in boldface were mapped as framework loci at LOD $>2.0$. Marker loci shown in italics were assigned to intervals only at $\mathrm{LOD}<2.0$. Loci with significant segregation distortion are marked with $* P<0.05$ and $* * P<0.01$. Bars to the left of linkage groups represent support intervals for the QTLs detected, with tick marks showing the LOD peaks. Abbreviations for environments are explained in "Materials and methods" 


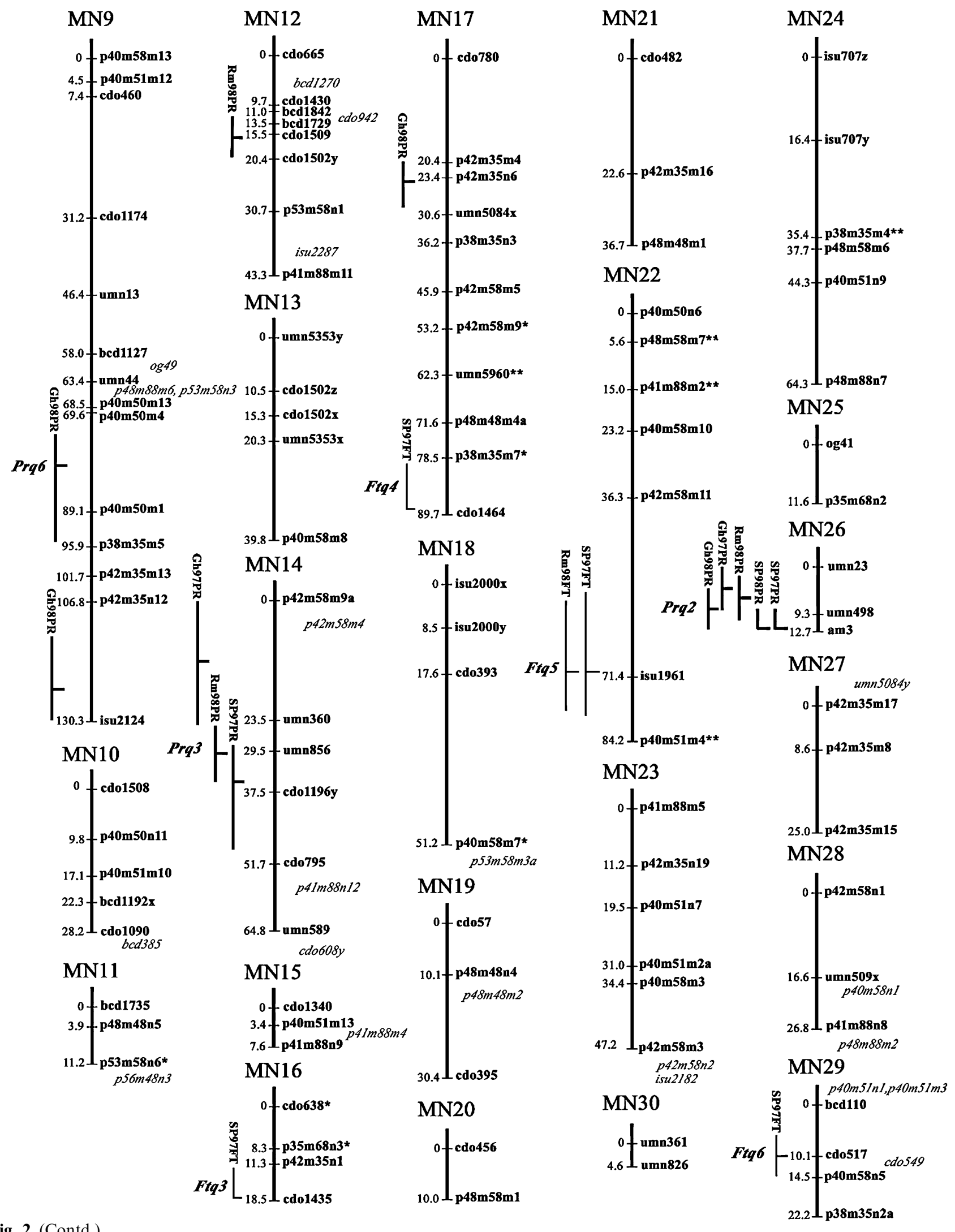

Fig. 2 (Contd.) 